\title{
INHERITANCE IN THE CARNATION, DIANTHUS CARYOPHYLLUS. V. THE CHEMISTRY OF FLOWER COLOR VARIATION, II
}

\author{
T. A. GEISSMAN, E. H. HINREINER AND E. C. JORGENSEN
}

Department of Chemistry, University of California, Los Angeles

Received July 18, 1955

N the first article of this series, Geissman and Menlquist (1947) described the chemical effects that accompanied alterations in the genetic constitution of carnations with respect to the factors $S, R$ and $M$. It was found that only $R$ affected the degree of nuclear hydroxylation of the anthocyanin pigments of the flowers. Cyanic forms that contained $R$ in homozygous or heterozygous condition contained cyanidin glycosides; the homozygous recessives $(r r)$ contained pelargonidin derivatives. At the time of that study the number of genetically analyzed non-cyanic forms was limited, and of the whites and yellows only $r r$ specimens were at hand. It was found that these white and yellow $r$ flowers (which contain no anthocyanins) did contain the flavonol kampferol, the hydroxylation pattern of which is the same as that of pelargonidin. Furthermore, from a crimson form ("Woburn," Yy $y^{f l}$ IiAvar aSSRrmm $)^{1}$ were isolated kampferol and quercetin-the latter the flavonol corresponding in hydroxylation pattern to cyanidin, the anthocyanidin of $R$ - plants.

These results afforded a tentative basis for the suggestion that $R$ was not uniquely associated with the anthocyanidin structure but was a factor concerned in the hydroxylation pattern of the "B-ring" of both the anthocyanins and flavones.

The present study has extended the early observations, and includes an examination of the flavonoid constituents of (a) seven $r r$ cyanic flowers (reds and pinks) and (b) nine whites, of which eight were $r r$ whites and one an $R$ - white.

\section{MATERIALS AND METHODS}

\section{Cyanic forms}

Commercial carnations were purchased in the market. The following, with the genotype (for flower color) so far as it is known, ${ }^{2}$ were used (table 1 ).

The following description of the manner in which one of the varieties was treated is typical of the procedure that was followed:

The petals $(1450 \mathrm{~g})$ of Chalfonte were removed by cutting off the colored portion outside of the calyx, and macerated with methanol in a Waring Blendor. The resulting slurry was filtered through Celite and the marc reextracted with methanol four times. The combined extract was concentrated to about one liter, $800 \mathrm{ml}$ of $5 \%$ sulfuric acid was added, and the resulting solution concentrated by boiling (steam bath) until about $500 \mathrm{ml}$ of methanol had been removed. The deep red solution was filtered (see below) and extracted with ether. Removal of the ether by distillation

${ }^{1}$ The genetic designations are described by Geissman and MeHLquist (1947).

${ }^{2}$ We are grateful to Prof. G. A. L. MenLquist for the information concerning the genetic constitution of these flowers. 
TABLE 1

\begin{tabular}{l|l|l}
\hline \multicolumn{1}{c|}{ Color } & \multicolumn{1}{|c}{ Variety } & \multicolumn{1}{c}{ Color genotype } \\
\hline Deep pink & Chalfonte & $Y-I-A-S-r r M-$ \\
Salmon & Ida & $Y-I-A-$ ssrrmmsusu \\
Red & Tom Knipe & $Y-I-A-S-r r m m$ \\
Light pink & Light Pink Peter Fisher & $Y-I-A-S-r r M-S u-$ \\
Deep pink & Deep Pink Peter Fisher & $Y-I-A-S-r r M-$ susu \\
Pink & Pink Spectrum & $Y-I-A-$ ssrmm \\
Red & Red Spectrum & $Y-I-A-S-r r m m$ \\
\hline
\end{tabular}

left a crystalline residue that weighed $4.0 \mathrm{~g}$. This material appeared to be a sapogenin, since it gave a magenta color with acetic anhydride-sulfuric acid (LiebermannBurchard reaction); but because it gave negative tests for flavonols, it was not examined further at the time.

The gummy residue from the filtration of the hydrolyzate was extracted exhaustively with ether, affording $8.62 \mathrm{~g}$ of a brownish-yellow solid. This was acetylated by boiling $1.5 \mathrm{~g}$ with acetic anhydride $(15 \mathrm{ml})$ and sodium acetate $(1.5 \mathrm{~g})$. The resulting flavonol acetate $(0.75 \mathrm{~g})$ formed cream-colored needles after recrystallization from ethanol, and had m.p. $185-186.5^{\circ} \mathrm{C}$.

In the same way, crude flavonol acetates were obtained from each of the seven flowers. These had the following properties (table 2):

The results of the mixed melting-point determinations afforded no unambiguous answer to the question of the identity of the flavonol acetates, probably because of their contamination with other substances. Since attempts to "purify" the acetates by recrystallization could have resulted in the removal of small amounts of quercetin or kampferol, recrystallization would have vitiated the whole purpose of this approach, which was to determine whether kampferol or quercetin, or both, were present in the flowers.

\section{Paper chromatography}

Ten mg of each of the crude acetates was dissolved in a mixture of $1 \mathrm{ml}$ of methanol and $1 \mathrm{ml}$ of water to which a drop of concentrated hydrochloric acid was added, and

TABLE 2

\begin{tabular}{l|l|l|l}
\multicolumn{1}{c|}{ Variety } & $\begin{array}{c}\text { M.p. of crude flavonol } \\
\text { acetate }\end{array}$ & \multicolumn{2}{|c}{ M.p. of mixture with } \\
\hline Chalfonte & $\begin{array}{c}\text { Kampferol } \\
\text { tetraacetate* }\end{array}$ & $\begin{array}{c}\text { Quercetin } \\
\text { pentaacetate* }\end{array}$ \\
\hline Ida & $185-186.5^{\circ} \mathrm{C}$. & $180-185^{\circ} \mathrm{C}$. & $170-175^{\circ} \mathrm{C}$. \\
Tom Knipe & $185-190^{\circ}$ & $179-186^{\circ}$ & $173.5-177^{\circ}$ \\
L. P. Peter Fisher & $188-189^{\circ}$ & $180-185^{\circ}$ & $172-180^{\circ}$ \\
D. P. Peter Fisher & $182-185^{\circ}$ & $179-183.5^{\circ}$ & $171-180^{\circ}$ \\
Red Spectrum & $183-187^{\circ}$ & $175-184^{\circ}$ & $167-185^{\circ}$ \\
Pink Spectrum & $185-188^{\circ}$ & $181-187^{\circ}$ & $170-184^{\circ}$ \\
\hline
\end{tabular}

${ }^{*}$ m.p. of kampferol tetraacetate, $182^{\circ} \mathrm{C}$; m.p. of quercetin pentaacetate, $195^{\circ} \mathrm{C}$. 
the solution refluxed for one hour. The cooled solution was applied to Whatman No. 1 paper $(25 \mu \mathrm{l})$ and the chromatogram developed with butanol (1 part)-27\% acetic acid (1 part). Authentic samples of quercetin and kampferol, and a sample of the flavonol acetate from "Woburn," treated as above, were run on the same sheet.

The results were clear and unambiguous. Kampferol was clearly visible in all of the pink and red genotypes, and quercetin was absent from these but clearly visible in the "Woburn" sample.

\section{Whites}

Eight "white" clones were furnished by Prof. G. A. L. MEHLquIST, whose breeding experiments had established their genotypes as follows:

\begin{tabular}{ll} 
Clone no. & \multicolumn{1}{c}{ Genotype } \\
$49040-1$ & $y y I-A-S-R-M-$ \\
$49041-5$ & YYIIaaSSrrmmSuSu \\
$51622-1$ & $a-$-white from selfing 49041-5; same genotype \\
$51622-7$ & $a$-white from selfing 49041-5; same genotype \\
$49041-6$ & $\begin{array}{l}a-- \text { white, sister seedling to 49041-5; probably same } \\
\text { genotype }\end{array}$ \\
$49086-5$ & $y y I I A A S \operatorname{Sr} M M$ \\
$49086-8$ & $y y I I A A S \operatorname{SrMM}$ \\
$51632-3$ & $y y I i A-S-\operatorname{rrMM}$
\end{tabular}

A sample of the petals of each of these ${ }^{3}$ was dried in a vacuum desiccator over sulfuric acid and ground to a powder. A $100 \mathrm{mg}$ portion was extracted with hot methanol, and a sample of the methanol extract, along with the marc, hydrolyzed by heating with $5 \%$ sulfuric acid for 2 hours. The cooled solution was extracted four times with $1 \mathrm{ml}$ portions of ethyl acetate and the extract concentrated in a gentle stream of air to about $0.5 \mathrm{ml}$. Ethanol was added to make the volume $1 \mathrm{ml}$. Samples of about 10 $\mu l$ of the final solution were chromatographed on Whatman No. 1 paper along with authentic specimens of quercetin, kampferol and apigenin. After drying, the chromatograms were sprayed with $2 \%$ alcoholic aluminum chloride to develop the brightly green-yellow fluorescence characteristic of 3-hydroxyflavones.

All of the white clones contained kampferol, but only 49040-1 contained quercelin as well. Apigenin was not observed to be present in these whites.

It is of interest to note that chromatograms of the original methanol extracts of the $y$-whites (49086-5, 49086-8, 51632-3) and the $a$-whites (51622-1, 51622-7, 49041-6) were clearly distinguishable from each other. The chemical differences between these two kinds of flowers cannot yet be described, but the identification of the components of these (complex) chromatograms will be undertaken in an effort to determine the chemical effects of the $A$ and $Y$ factors.

\section{DISCUSSION}

The present findings support the suggestion made earlier that the $R$ factor in carnations controls the degree of oxidation of the B-ring in the flavonoid constituents of

${ }^{3}$ Prof. B. Lennart Johnson of the Division of Ornamental Horticulture of U.C.L.A. was kind enough to grow the plants from rooted cuttings furnished by Prof. MertouisT. 
the flowers. The effect of $R$ is shown in the following summary:<smiles>O=c1c(O)c(-c2ccc(O)cc2)oc2cc(O)cc(O)c12</smiles>

kampferol

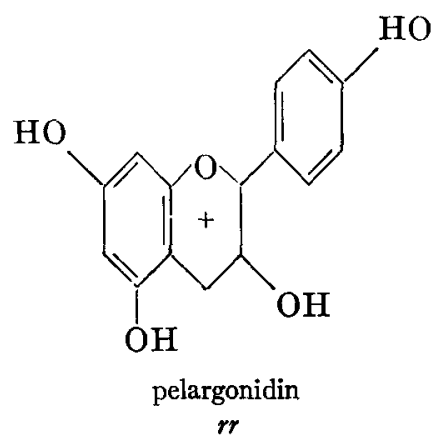<smiles>O=c1c(O)c(-c2ccc(O)c(O)c2)oc2cc(O)cc(O)c12</smiles>

quercetin<smiles></smiles>

Since kampferol is found along with quercetin in $R$ - flowers, it is surprising that cyanidin alone is present in the cyanic forms that carry $R$-. Indeed, this point now requires reexamination. In the early work (GEISSMAN and MEHLQuist 1947) the nature of the cyanic pigmentation was established by the application of the color tests of RoBINSON and RoBINSON (1931) to petal extracts. It was remarked at that time that while the presence of cyanidin as a contaminant of pelargonidin could be detected by these color tests, small amounts of pelargonidin could escape detection in the presence of cyanidin. With the aid of chromatographic methods, the presence of either pelargonidin or cyanidin as a concomitant of the other can now be detected. Experiments to reexamine this point are to be performed.

The $R$ factor of carnations resembles in its effects the $M$ factor of the snapdragon (Antirrhinum majus), as described by GeIssman, Jorgensen and Johnson (1954), Jorgensen and Geissman (1955a, b), and Geissman and Harborne (1955). This factor controls hydroxylation in the B-ring of the flavonoid pigments of this flower, acyanic $M$ - flowers containing luteolin and apigenin, cyanic $M$ - flowers luteolin, apigenin, quercetin and cyanidin, while $\mathrm{mm}$ flowers contain only apigenin if acyanic, and apigenin, kampferol and pelargonidin when cyanic.

The present results further emphasize the importance of examining the noncyanic pigments in studies of the chemical effects of genetic changes. Carnations and snapdragons both contain factors whose phenotypic expression appears to be an alteration of the structures of the anthocyanin pigments of the pink to magenta flowers, but which in reality exert a structural control at another level of synthesis. 
It is hoped that further studies of selected carnation genotypes will make it possible to define more exactly the nature of the chemical reactions at which these and other factors exert their control.

\section{ACKNOWLEDGMENTS}

The authors wish to express their gratitude to Prof. G. A. L. Menlquist and Prof. B. L. Johnson for their invaluable aid in preparing and growing the special genetic material needed for this study. The support of the U. S. Public Health Service and of Eli Lilly and Co. is gratefully acknowledged.

\section{LITERATURE CITED}

Geissman, T. A., and J. B. Harborne, 1955 The chemistry of flower pigmentation in Antirrhinum majus. IV. The albino $(-m m-n n)$ form. Arch. Biochem. Biophys. 65: 447-454.

Geissman, T. A., E. C. Jorgensen, and B. L. Johnson, 1954 The chemistry of flower pigmentation in Antirrhinum majus color genotypes. I. The flavonoid components of the homozygous $P, M, Y$ color types. Arch. Biochem. Biophys. 49: 368-388.

Geissman, T. A., and G. A. L. Merlquist, 1947 Inheritance in the carnation, Dianthus caryophyllus. IV. The chemistry of flower color variation, I. Genetics 32: 410-433.

JoRGENSEN, E. C., and T. A. GeIssman, 1955a The chemistry of flower pigmentation in Antirrhinum majus color genotypes. II. Glycosides of $P P m m Y Y, P P M M Y Y, p p m m Y Y$, and $p p M M Y Y$ color genotypes. Arch. Biochem. Biophys. 54: 72-82.

1955b The chemistry of flower pigmentation in Antirrhinum majus color genotypes. III. Relative anthocyanin and aurone concentrations. Arch. Biochem. Biophys. 55: 389-402.

Robinson, G. M., and R. Robinson, 1931 A survey of the anthocyanins. Biochem. J. 25: 16871705 . 